\title{
OVERLOOKING THE CRIMINALLY COMPASSIONATE: WHAT ARE THE IMPLICATIONS OF PROSECUTORIAL POLICY ON ENCOURAGING OR ASSISTING SUICIDE?
}

\author{
ALEXANDRA MULLOCK* \\ Centre for Social Ethics and Policy, Institute for Science, Ethics, and Innovation, \\ School of Law, University of Manchester
}

The decision of the House of Lords in the case of Purdy compelled the Director of Public Prosecutions (DPP) to promulgate guidance as to the exercise of prosecutorial discretion with respect to those suspected of an offence under the Suicide Act 1961. Consequently, the Policy for Prosecutors in Respect of Cases of Encouraging or Assisting Suicide now sets out determining factors for potential culpability in encouraging or assisting suicide. This paper discusses the implications of the Policy, particularly with respect to the role of compassion as a key determining factor which effectively decriminalises acts of assisting or encouraging suicide in the majority of cases, despite such acts remaining technically criminal. Following the DPP's assertion that the location of the actual suicide is irrelevant to the prosecutorial decision, this article considers whether some elements of the Policy might belie this assertion. The apparently heightened risk of prosecution now faced by doctors and other healthcare professionals and workers is also considered. Finally, in light of the apparent prosecutorial endorsement of compassionate assisted suicide, this article questions whether we might now expect the imminent legalisation of assisted suicide.

Keywords: Assisted suicide, prosecutorial policy, suicide tourism, compassion, suffering, discrimination, healthcare professionals.

This paper is an output of the AHRC-funded project, The Impact of the Criminal Process on Health Care Ethics and Practice, see further < http://www.law. manchester.ac.uk/research/hccriminalprocess/index.html>. I am extremely grateful to Dr Suzanne Ost and Dr John Coggon for their invaluable comments on earlier drafts. Thanks are also due to Dr Charles Erin and to the two anonymous reviewers. Any errors are, of course, my own. 


\section{INTRODUCTION}

Following the successful endeavours of Debbie Purdy ${ }^{1}$ to compel the Director of Public Prosecutions (DPP) 'to clarify what his position is as to the factors that he regards as relevant for and against prosecution in this very special and carefully defined class of case', ${ }^{2}$ the 'Policy for Prosecutors in Respect of Cases of Encouraging or Assisting Suicide' (the Policy) now sets out determining factors for potential culpability in encouraging or assisting suicide. ${ }^{4}$ The offence of encouraging or assisting suicide replaces the offence of 'aiding, abetting, counselling, or procuring the suicide of another' under the Suicide Act $1961 .^{5}$ To the surprise of many, and in their final decision before reconvening as the Supreme Court, the House of Lords departed from their earlier decision in the case of Pretty, ${ }^{6}$ by ruling that the 'article 8 rights ${ }^{7}$ of Ms Purdy entitle her to be provided with guidance from the Director as to how he proposes to exercise his discretion under section 2(4) of the 1961 (Suicide) Act'.

Accordingly, the DPP published his interim guidelines ${ }^{9}$ in September 2009 at the same time as launching a public consultation exercise in

${ }^{1}$ Ms Purdy, who suffers from multiple sclerosis, made her application for Judicial Review (with the support of Dignity in Dying), commencing in the High Court with $R$ (On the Application of Purdy) $v$ DPP [2008] All ER (D) 284, then proceeding to the Court of Appeal; $R$ (On the Application of Purdy) $v$ DPP [2009] All ER (D)197, culminating in $R$ (on the application of Purdy) $v$ Director of Public Prosecutions (Society for the Protection of Unborn Children Intervening) [2009] UKHL 45, [2009] WLR 403; [2010] 1 A.C. 345(HL).

2 Ibid. HL decision at para 55.

3 Available at <http://www.cps.gov.uk/publications/prosecution/assisted suicide_policy.html $>$.

${ }^{4}$ Where the potential offence under s 2 of the Suicide Act 1961 occurred on or after February 1 2010, the amendment provided by s 59 and Schedule 12 of the Coroners and Justice Act 2009 applies. Thus, the prosecution must prove that the suspect did an act capable of encouraging or assisting the suicide or attempted suicide of another person; and the suspect's act was intended to encourage or assist suicide or an attempt at suicide.

5 S 2(1) of the Suicide Act 1961 provided that 'A person who aids, abets, counsels or procures the suicide of another or an attempt by another to commit suicide, shall be liable on indictment for a term not exceeding 14 years'.

${ }^{6} \mathrm{R}$ (On the Application of Dianne Pretty) $v$ DPP (2001) WL 1171775 (HC); R (On the Application of Dianne Pretty) v DPP (2001) WL 1423045 (HL); Pretty $v$ UK Application no.2346/02 (ECtHR) (2002) 35 EHRR1, ECHR.

7 Art. 8 of the European Convention on Human Rights (ECHR) provides that; (1) Everyone has the right to respect for his private and family life, his home, and his correspondence. (2) There shall be no interference by a public authority with the exercise of this right except such as in accordance with the law and is necessary in a democratic society in the interests of national security, public safety, or the economic well-being of the country, for the prevention of disorder or crime, for the protection of health or morals, or for the protection of the rights and freedoms of others.

8 Purdy HL at para 106 (n 2, above).

9 Interim Policy for Prosecutors in respect of Cases of Assisted Suicide, Issued by The Director of Public Prosecutions, September 2009. Available on $<$ www.cps.gov.uk>. 
order to gather views upon which to determine the final guidelines, which were then released in February 2010. The final guidelines present 16 factors in favour of prosecution and six against, as follows:

Public interest factors tending in favour of prosecution:

(1) The victim was under 18 years of age;

(2) The victim did not have the capacity (as defined by the Mental Capacity Act 2005) to reach an informed decision to commit suicide;

(3) The victim had not reached a voluntary, clear, settled, and informed decision to commit suicide;

(4) The victim had not clearly and unequivocally communicated his or her decision to commit suicide to the suspect;

(5) The victim did not seek the encouragement or assistance of the suspect personally or on his or her own initiative;

(6) The suspect was not wholly motivated by compassion; for example, the suspect was motivated by the prospect that he or she or a person closely connected to him or her stood to gain in some way from the death of the victim;

(7) The suspect pressured the victim to commit suicide;

(8) The suspect did not take reasonable steps to ensure that any other person had not pressured the victim to commit suicide;

(9) The suspect had a history of violence or abuse against the victim;

(10) The victim was physically able to undertake the act that constituted the assistance him or herself;

(11) The suspect was unknown to the victim and encouraged or assisted the victim to commit suicide by providing specific information via, for example, a website or publication;

(12) The suspect gave encouragement or assistance to more than one victim who were not known to each other;

(13) The suspect was paid by the victim or those close to the victim for his or her encouragement or assistance;

(14) The suspect was acting in his or her capacity as a medical doctor, nurse, other healthcare professional, a professional carer [whether for payment or not], or as a person in authority, such as a prison officer, and the victim was in his or her care;

(15) The suspect was aware that the victim intended to commit suicide in a public place where it was reasonable to think that members of the public may be present;

(16) The suspect was acting in his or her capacity as a person involved in the management or as an employee (whether for payment or not) of an organisation or group, a purpose of which is to provide a physical environment (whether for payment or not) in which to allow another to commit suicide.

Public interest factors tending against prosecution: 
(1) The victim had reached a voluntary, clear, settled, and informed decision to commit suicide;

(2) The suspect was wholly motivated by compassion;

(3) The actions of the suspect, although sufficient to come within the definition of the offence, were of only minor encouragement or assistance;

(4) The suspect had sought to dissuade the victim from taking the course of action which resulted in his or her suicide;

(5) The actions of the suspect may be characterised as reluctant encouragement or assistance in the face of a determined wish on the part of the victim to commit suicide;

(6) The suspect reported the victim's suicide to the police and fully assisted them in their enquiries into the circumstances of the suicide or the attempt and his or her part in providing encouragement or assistance.

Whilst the final Policy reflects the general tone of the interim policy - so that the message that it is not in the public interest to prosecute a person who has compassionately and reluctantly assisted in the suicide of a determined and competent adult endures - some changes have been made. Most notable amongst these changes is 'the apparently heightened risk of prosecution'10 now faced by healthcare professionals, together with the removal of the factor relating to illness or disability which featured in the interim policy, such that the final guidelines focus more on the motivations of the suspect than the health of the victim. Despite some clear differences between the interim and final policy, the DPP has stressed that the likelihood of prosecution remains unchanged. The DPP's message, that it remains a criminal offence to encourage or assist in suicide, ${ }^{11}$ is also perhaps contradictory because, as it will be argued here, the Policy has precisely the effect of sanctioning compassionately motivated assisted suicide, with compassion as the key determining factor which potentially places an act which remains criminal beyond the reach of the criminal courts.

This paper considers the implications of the Policy, both in relation to key specific factors and with respect to the wider implications such a policy might bring to bear on this area of law. Because these developments have stemmed from the phenomenon of suicide tourism, I begin with some consideration of aspects of the Policy which might influence where (at home or at Dignitas) people seek assistance in suicide, in order

${ }_{11}^{10}$ John Coggon, 'Doctors and Assisted Suicide' (2010) 340 BMJ 547.

11 At para 6 of the policy (see n 4, above), the DPP states: 'This policy does not in any way "decriminalise" the offence of encouraging or assisting suicide. Nothing in this policy can be taken to amount to an assurance that a person will be immune from prosecution if he or she does an act that encourages or assists the suicide or the attempted suicide of another person'. 
to assess whether the location of the assisted suicide is not, as the DPP asserts, relevant to the prosecutorial decision.

My focus then shifts to the issue of compassion. Despite there being no presumptive weighting to any of the factors, ${ }^{12}$ it will be argued that aside from some of the more obviously harmful factors, ${ }^{13}$ which might even call into question whether the victim's death should be treated as a homicide rather than a suicide, the key issue is the motivation of the assistor and whether he or she was 'wholly motivated by compassion'. With respect to the moral underpinnings of the Policy, the factor pertaining to autonomy might be seen as equally crucial, however, because it is assisting in suicide rather than mercy-killing that is under scrutiny, compassionate assistance arguably depends on there being an autonomous desire for suicide. Moreover, I contend that the very concept of compassion, in this context, assumes autonomy on the part of the victim. Thus, assessing compassion will be the crucial issue in the vast majority of cases which fall under prosecutorial scrutiny. Leading on from this, I contend that the overt tolerance of compassionate assisted suicide will increasingly highlight the futility of continued prohibition in the face of a Policy which blatantly confronts the inadequacy of the criminal law in this area. With this in mind, this paper will consider the implications of denying the relevance of the health of the victim whilst also seeking to deter any medical involvement, arguing that whilst recognising compassion as the key determining issue presents a sound basis upon which to found such a Policy, other aspects of the Policy are less sound.

\section{BACKGROUND}

In consideration of the factors which preceded the Policy, the DPP may be understandably anxious not to be seen as usurping the role of the legislature by legitimising an assisted suicide. However, a number of factors have forced his hand. As Keown has observed, the DPP was '[p]laced in this invidious position (by a ruling which was, with respect, unsound if not unconstitutional)'. ${ }^{14}$ Consequently, the DPP was charged with the

12 John Coggon has observed that none of the factors ' $\ldots$ is necessarily 'heavier' than others, and no one can find an answer simply by totting up factors for and against and seeing which list is longer'. See J Coggon, 'Prosecutorial Policy on Encouraging and Assisting Suicide - How Much Clearer Could It Be?' (2010) JME 36(7) 381-82.

13 Such as the victim lacking capacity or being pressured into committing suicide.

14 J Keown, 'Dangerous Guidance' (2009) 159 New LJ 1718. Glenys Williams is also critical of the decision in Purdy, arguing that '.. ordering the DPP to publish a policy guidance document which effectively decriminalises assisted suicide, is not the way in which the law can or should be changed in the UK'. See 'Assisting Suicide, the Code for Crown Prosecutors and the 
task of producing a policy which would remain consistent with the existing practice, ${ }^{15}$ while simultaneously providing a sufficient degree of clarification as well as attempting not to tie the hands of the prosecution with respect to future cases. The circumstances which placed the DPP in this unenviable position are interesting. Most significantly, the availability of assisted suicide abroad has encouraged those in distress over the prospect of a difficult and undignified end to view the assisted suicide as a realistic option. Doubt over whether it was even an offence under the Suicide Act to assist a person to travel abroad for suicide prevailed until the DPP's recent assertion that the location of the suicide is irrelevant. ${ }^{16}$ Thus, in a climate of jurisdictional uncertainty, the current DPP's predecessor ${ }^{17}$ initiated the prosecutorial approach to 'suicide tourism' with the decision that it was not in the public interest to prosecute the widow of the first Briton, Reg Crew, ${ }^{18}$ whose demise fell under the media spotlight after he travelled abroad for an assisted suicide in 2003.

In the intervening years not a single prosecution has followed an assisted suicide which occurred abroad. ${ }^{19}$ In September 2008, the

DPP's Discretion' (2010) 2 Common Law World Review 2010 181-203. See also J Finnis, 'The Lords Eerie Swansong: A note on R (Purdy) v DPP' (2009) Oxford Legal Studies Research Paper No.31/2009<http://ssrn.com/ abstract $=1477281>$.

15 Thereby rationalising why no prosecutions have followed on from suicides which have occurred abroad.

16 In his article, 'Suicide in Switzerland: Complicity in England?', [2009] Crim L R 335, Professor Michael Hirst argued that the suicide would have to occur in this jurisdiction in order for an offence to be committed under the Suicide Act. This issue has been disputed, see for example, J Coggon, 'Assisting Death Tourism: Possible Prosecution or Pragmatic Immunity' $<$ http://www.ccels.cf. ac.uk/archives/issues/2008/coggon.pdf >. In Purdy, the House of Lords considered the issue of territoriality and were divided on the issue, however, in his policy, the DPP states (see n 4, at para 8) that the act which may constitute criminal assistance or encouragement must be committed in England/Wales, although the suicide or attempt may take place anywhere in the world including England and Wales. It may be argued, however, that this is merely the DPP's opinion and the question has yet to be legally resolved. See also, the former Lord Justice of Appeal, Richard Buxton's case comment on Purdy, 'Complicity in Suicide Abroad' (2010) 126 LQR 1-5.

17 Prior to the appointment of the current DPP (Keir Starmer), the office of his predecessor, Sir Ken McDonald, determined that in none of the cases involving an assisted suicide abroad was it in the public interest to pursue a prosecution.

$18 \mathrm{Mr}$ Crew, who was terminally ill, travelled to Dignitas with the obvious assistance of his wife in 2003. The DPP concluded that it was not in the public interest to prosecute Mrs Crew.

19 According to Lord Hope in Purdy, (see n 2 above, at para 30) at the time of the hearing (July 2009), 115 Britons had travelled abroad for an assisted suicide. Of those cases, eight had been referred to the DPP for a decision as to whether the assistors should be prosecuted. In six of these cases, the DPP determined that there was insufficient evidence and in two cases, 
death of Daniel James ${ }^{20}$ and his parents' reluctant role in assisting his suicide prompted speculation that the first prosecution for assisting in a suicide tourism case might occur, but even assistance in the suicide of such a young (and not terminally ill) person did not tip the public interest scales in favour of prosecution. Despite finding that the defendants had satisfied the 'evidential test', ${ }^{21}$ the DPP cited Daniel's previous suicide attempts, his fiercely independent spirit, and the fact that the defendants had relentlessly implored Daniel to reconsider, as crucial to the decision that it was not in the public interest to pursue a prosecution. In a clear attempt to assuage the fears of Debbie Purdy, ${ }^{22}$ the DPP took the unprecedented step of publishing the reasons for the decision in James. ${ }^{23}$ The House of Lords, however, agreed with Ms Purdy that whilst the guidance provided by the DPP's decision in the case of Daniel James was 'generally helpful', ${ }^{24}$ it did not provide sufficient clarity as to how the Code for Crown Prosecutors should be applied generally to a case of assisted suicide, or how the DPP exercises his discretion over the decision to prosecute.

Thus, the policy now confirms that, with respect to the investigation of one suspected of assisting in suicide, evidence of compassion and the apparent absence of any selfish motivation will effectively place the suspect in the position of a legitimate assistor in suicide, provided of course that the so-called victim was a competent adult exercising his or her autonomous desire for suicide. Before considering the wider implications of the role of compassion in legitimising an assisted suicide and how the practical implications of assessing compassion might be unravelled, it is interesting to consider whether the Policy genuinely takes no account of the location of the actual suicide, or whether,

despite there being sufficient evidence, it was decided there was insufficient public interest. Other cases appear to have been discontinued by the police on public interest grounds.

20 A 23-year-old man who sustained serious spinal injuries resulting in tetraplegia from a rugby accident.

21 There being, according to the DPP, sufficient evidence to justify a prosecution on the basis that there would be a realistic prospect of conviction. See Decision on Prosecution - The Death By Suicide of Daniel James, 9 December 2008, <www.cps.gov.uk/news/nationalnews/death_by_suicide_of_ daniel_james.html>. For comment, see A Mullock, 'Prosecutors Making (Bad) Law?', (2009) 17 Med L R 209-99.

22 At the time (December 2008), Ms Purdy had just failed in the High Court in her first attempt to have the DPP promulgate a code pertaining to those who assist in a suicide abroad.

23 See $n 22$.

24 See Purdy HL, (n 2, above), Lord Brown at para 85. Lords Neuberger and Brown agreed that whilst the decision in James made it '.. pretty clear... how the Director approaches these cases...' (at para 97), the decision also highlighted just how inapplicable the Code provisions are. 
as previous policy might suggest, one is far less likely to be prosecuted when the victim dies abroad.

\section{COMPLICITY IN ENGLAND, SUICIDE IN ...?}

On the face of it, the Policy takes no account of the jurisdiction within which the victim's suicide occurs, focusing only on where the act or acts of assistance or encouragement occurred. Thus, an assisted suicide which occurs in London is legally equivalent to an assisted suicide which occurs in Zurich. However, several of the factors which are clearly intended to deter (certain) people from providing more significant assistance in suicide will inevitably encourage travel to a permissive jurisdiction such as Switzerland. This may not be entirely unexpected, given that the Policy was born as a consequence of the availability of assisted suicide abroad, which ignited Ms Purdy's desire to understand how prosecutorial discretion is exercised in relation to suicide tourism. Nevertheless, it is worth considering whether the DPP's assertion that the location of death is irrelevant withstands scrutiny.

Consider the following factors tending in favour of prosecution: the victim was unknown to the suspect and provided assistance or encouragement via a publication or website; the suspect assisted more than one person; the suspect was acting in a medical capacity; and the suspect was a person involved in an organisation or group whose purpose is to provide a physical environment for an assisted suicide. ${ }^{25}$ Recall that if the actions of the suspect, although evidentially sufficient, might be regarded as constituting only minor encouragement or assistance, ${ }^{26}$ it will count as a factor tending against prosecution. These factors are clearly aimed at deterring any individuals or organisations from providing any advice service or assisted suicide facility, in order to avoid the emergence of any Dignitas-type organisation operating within the jurisdiction. Superficially, this may be viewed as a positive objective, because

25 See respectively; para 43(11), (12), (14), (16) of the Policy (see n 4, above).

26 Para 45(3) of the Policy (see $n$ 4, above). We might assume that providing the method/means of suicide, for example, helping to collect pills or helping an incapacitated person to consume a fatal overdose, would not constitute 'minor encouragement or assistance'. Evidence suggests that the DPP has a strict approach to any form of determinative assistance in suicide. For example, Kay Gilderdale was prosecuted for attempted murder for her role in her daughter's suicide. See BBC news 'CPS Defends Charging Gilderdale over ME Daughter Death' 26 January 2010, <www.news.bb.co.uk/1/hi/ England/sussex/8481055.stm $>$. Following Gilderdale's acquittal, the trial judge was scathing of the decision to pursue such a prosecution and in response to this criticism the DPP published a statement in defence of his decision. See <www.cps.gov.uk/news/press_statements/questions_about_ kay_gilderdale_decision/ $>$. 
it is indisputably desirable to discourage people from committing suicide. However, the Policy may merely succeed in encouraging people to seek help abroad, because no meaningful help is available at home. This approach may also encourage people to seek an assisted suicide sooner than they might otherwise because of the need to travel abroad to Switzerland whilst they remain able to do so. ${ }^{27}$ In Switzerland, ${ }^{28}$ an assisted suicide is currently legal, provided the person assisting acts in the absence of self-interest. Subject to Swiss narcotic law, physicians are permitted to prescribe lethal doses of barbiturate for the purposes of assisted suicide. ${ }^{29}$ Unlike other jurisdictions where assisted dying is permitted, Switzerland (or at least certain Swiss cantons) allows non-Swiss residents to avail themselves of the services of Swiss assisted suicide organisations such as Dignitas. ${ }^{30}$ Thus Dignitas, together with the physician employed by the organisation, will assess the medical grounds upon which the application for an assisted suicide rests, and provided there appear to be grounds for the death wish, assistance may be forthcoming. Although there is some limited medical assessment of the person seeking an assisted suicide, there is no specific requirement that the person be terminally ill or even suffering unbearably. Unsurprisingly, this has invited criticism of Swiss law, particularly with respect to the activities of Dignitas. ${ }^{31}$ As Seale has observed, 'Swiss cases entail more women than men, and one in five

27 Indeed, this was one of the arguments put forward in Purdy. See HL decision, para 31 (see $n$ 2, above).

28 Art. 115 of the Swiss Penal Code states; 'A person who, for selfish motives, aids, or abets another person in suicide will be punished with imprisonment up to 5 years'. For a full examination of the Swiss law, see J Griffiths, H Weyers and M Adams, Euthanasia and the Law in Europe (Hart Publishing 2008).

29 A doctor writing a prescription for assistance in suicide must act according to Art. 11 of the narcotics law, which requires that the drug be used, dispensed and prescribed according to the established rules of medical practice. An administrative court ruling in Zurich in 1999 (Verwaltungsgericht des Kantons Zurich, Entscheid der 3 Kammer VB Nr 99.00145, 1999) added the requirement that there be 'a condition indisputedly leading to death'; however, the court failed to specify which conditions should be covered by this term and even raised the question of whether mental conditions might be included. In 2006, the Swiss Federal Supreme Court (Schweizerisches Bundesgericht, Entscheid 2A. 4812006, 2006) ruled that a incurable, permanent, serious mental disorder can be comparable with a serious physical condition, thus a doctor who prescribes lethal drugs for a mentally ill patient does not necessarily violate the rules of medical practice in this regard. See Griffiths and others (ibid).

30 Founded in 1998 by the Swiss lawyer, Ludwig Minelli, Dignitas is a nonprofit organisation set up to assist those with 'medically diagnosed hopeless or incurable illness, unbearable pain or unendurable disabilities'.

31 See for example, 'Murky truth behind Swiss suicide 'clinic' Dignitas', Times Online (Oct 25 2008) <www.thetimes.co.uk/tto/health/article1963892. ece $>$. 
has no fatal condition but rather, for example, arthritis, osteoporosis, "general weakness," blindness, or mental disorders, usually depression'. ${ }^{32}$ Although no validated statistics exist for the assisted suicide cases in Switzerland, some of the cases ${ }^{33}$ involving UK citizens dying at Dignitas clearly support Seale's observation and so it seems that we have good reason to be concerned. If the Policy succeeds in keeping down the numbers of assisted suicide within the jurisdiction only at the cost of exporting suicidal UK citizens to a jurisdiction where an assisted suicide is too easily available, this approach is less than satisfactory.

The factors mentioned above also raise interesting questions about the relationship between law and morality in this context. The question of which acts of assistance should or should not invite condemnation, or in fact which people should be more or less likely to be effectively exonerated, ${ }^{34}$ is also difficult to resolve. As Lord Lane CJ observed in Hough, 'in terms of gravity it could range from the borders of cold-blooded murder down to the shadowy area of mercy killing or common humanity'. ${ }^{35}$ Thus, one might question whether the location of the suicide and/or the extent of the degree of assistance, for example, should determine the moral or legal character of an act? Two recent cases involving parental assistance in suicide provide an illuminating comparison. As previously mentioned, the parents of Daniel James escaped prosecution after they escorted their son to Zurich for an assisted suicide. In contrast, Kay Gilderdale was charged with attempted murder following her role in her daughter Lyn's suicide. ${ }^{36}$ Clearly, Gilderdale's role in her daughter's death was more proactive than that of $\mathrm{Mr}$ and Mrs James, a fact which compelled the DPP to reject Gilderdale's guilty plea for assisting in suicide and to instead pursue charges for attempted

32 C Seale, 'Do It Properly or Not at All' (2010) 340 BMJ C1719.

33 For example, Robert and Jennifer Stokes, who died at Dignitas in 2003, were both relatively young and neither suffered from a terminal or even serious illness. More recently, an 85-year-old man, Sir Edward Downes, who suffered from only age-associated health problems, died at Dignitas together with his terminally ill wife, aged 74 . While Mr and Mrs Stokes travelled unaided to Dignitas, the Downes' son, Caractacus Downes, was investigated following his role in accompanying his parents to Dignitas. Despite being a beneficiary to his parents' considerable estate, Caractacus was deemed by the DPP to have been 'wholly motivated by compassion'. See 'No assisted suicide charge for son of Sir Edward Downes', BBC news, March 192010 $<$ www.news.bbc.co.uk/1/hi/englan/london/8576218.stm $>$.

34 For example, the policy indicates that a person acting in their capacity as a healthcare worker is more likely to be prosecuted than a relative who assists in suicide.

$35 R v$ Hough (1984) 6 Cr App Rep (S) 406 at 407.

36 See n 27 , above. 
murder. ${ }^{37}$ Notwithstanding the DPP's contention that Gilderdale's actions had crossed the line from complicity in suicide to active killing (evidence of which was rejected by the jury), in reality both victims, being physically incapacitated, were equally reliant on the assistance provided by the defendants. Both victims had attempted suicide previously. Both victims demonstrated an equally clear, settled, and competent wish to die. We might wonder; if $\mathrm{Mr}$ and Mrs James had obtained a fatal dose of barbiturates in order to help Daniel to die in England, would the DPP's decision (not to prosecute) have been different? Or, does the assistance of the Swiss volunteer nurse who would have overseen Daniel's suicide at Dignitas mean that the assistance provided by $\mathrm{Mr}$ and Mrs James is morally different to the assistance provided by Kay Gilderdale?

Navigating this moral minefield is clearly going to be challenging. However, the first post-policy case involving an assisted suicide occurring within the jurisdiction suggests that the DPP's assertion regarding location might be more convincing than expected. Michael Bateman was investigated after assisting in his wife's suicide by assembling helium gas apparatus and placing a plastic bag over her head before she herself turned on the helium supply and tightened the bag. ${ }^{38}$ Clearly, Bateman's actions could hardly be described as constituting 'only minor assistance or encouragement', but nevertheless the Crown Prosecution Service concluded that Bateman had been wholly motivated by compassion and consequently it was not in the public interest to prosecute him. Evidently, this decision supports my earlier contention that assessing the suspect's motivation is the overriding issue in such cases, but the Bateman decision is also interesting as an example of what might be a growing phenomenon of 'Do-It-Yourself' assisted suicides. Whilst it seems that Mrs Bateman experienced a humane death following an autonomous decision to die, others may be less fortunate. As Seale opines, ' $[\mathrm{B}]$ otched suicides assisted by amateurs and ill considered decisions to die by some of the most vulnerable people in society are the likely outcomes of the assisted dying policy of the DPP ....39 Although it seems unfair to lay the blame for botched suicides at the door of the $\mathrm{DPP}$, it is not unreasonable to contend that a greater willingness to

37 Kay Gilderdale was alleged to have assisted her daughter by initially passing morphine to her and then later, after Lyn lost consciousness, to have continued administering morphine until Lyn died.

38 Michael Bateman's wife had been bedridden for years due to an undiagnosed condition. For details of the Bateman decision, see 'Assisted Suicide Charge Not in the Public Interest', < http://www.cps.gov.uk/news/press_release/ 120_10/> See also <http://www.telegraph.co.uk/news/uknews/7760266/ Man_who_helped_wife_commit_suicide_will_not_be_prosecuted.html >.

39 See n 33, above. 
exonerate relatives and friends (over those who might offer more expert assistance $)^{40}$ might, in addition to compelling people to travel abroad to die, have the effect of encouraging more people to take matters into their own hands. Thus, an increase in botched suicides presided over by (hopefully) well-meaning, but ill-informed relatives might be an unintended consequence of the Policy. ${ }^{41}$ It is also apparent that although the organisation Dignitas operates with inadequate safeguards, it does at least provide that a third party is involved in the decision to die and the subsequent suicide. In addition to facilitating a humane death, a third party might be seen as having an important role in seeking to ensure both that the victim has mental capacity and is acting autonomously in order to escape suffering. The involvement of a third party may also encourage the victim to reconsider and explore alternatives, a possibility which it seems the Policy has overlooked.

\section{WHOLLY MOTIVATED BY COMPASSION?}

'At the basis of compassion lies an identification with the sufferer as a fellow human being, a recognition that similar misfortunes may also befall one, insofar as one is human'. ${ }^{42}$

The second public interest factor tending against prosecution invites an assessment of whether 'the suspect was wholly motivated by compassion'. Similarly, the public interest factors tending in favour of prosecution direct prosecutors to consider whether the suspect was motivated by a prospective gain. ${ }^{43}$ The DPP advocates a "common sense approach ${ }^{, 44}$ to this issue, stating that the fact that a suspect has gained some benefit from the victim's death will not usually tend in favour of prosecution if it is shown that compassion was the only driving force behind the suspect's act. Naturally, this involves a retrospective assessment of the motivations which prompted the suspect's complicity in the suicide, and there are obvious practical difficulties in investigating the motives of a suspect following the death of perhaps the only person truly able to bear witness to the suspect's motives in any meaningful sense. Indeed, a complete lack of prosecutions following

40 Referring to the factors mentioned above (see $\mathrm{n} 26$, above), and the factor regarding healthcare workers, which is discussed further below.

41 For example, a terminally ill man, William Stanton, recently survived a suicide pact in which his wife, who was healthy, died. See 'I Botched Our Suicide Pact', The Sunday Times, November 1 2009. At < http://www. timesonline.co.uk/tol/news/uk/article6897964.ece>.

42 Liezl Van Zyl, Death and Compassion: A Virtue-based Approach to Euthanasia (Ashgate Publishing, Aldershot, 2000) 165.

43 See n 4, above, para 43(6) of the Policy.

44 Ibid, para 44 of the Policy. 
assisted suicides at Dignitas, some of which have undoubtedly yielded significant benefits to people involved in assisting the suicidal person, points to a trusting approach on this issue. Moreover, one might observe that in the absence of demonstrably evil motives, such as those displayed in the case of Mrs McShane ${ }^{45}$ - a woman in serious financial difficulty, who was convicted under the Suicide Act 1961 in the 1970s for attempting to persuade her mother to commit suicidea prosecution is highly unlikely. The fact that Mrs McShane's actions were captured on video assisted the prosecution in establishing a case against her, but such compelling evidence is extremely rare, and evidence of bad motive in such cases is almost certain to be elusive even where it exists. Of course, it may be argued that it does not require a criminal mastermind to feign compassion and conceal self-interest; however, as McShane illustrates, where there is bad motive, there may also be pressure, ${ }^{46}$ or at the very least, the potential victim will be unlikely to have demonstrated that they 'had reached a voluntary, clear, settled and informed decision to commit suicide'. ${ }^{47}$ Considering this point, factors tending against prosecution include: if there was evidence to suggest that the suspect had sought to dissuade the victim, ${ }^{48}$ and that the 'actions of the suspect may be characterised as reluctant encouragement or assistance in the face of a determined wish on the part of the victim to commit suicide'. ${ }^{49}$ Thus, when considered together, these factors arguably encourage a sensible assessment which seeks to ensure both that the victim was acting autonomously and that the suspect appeared to be motivated by nothing other than compassion.

Perhaps far more interesting than the practical implications of assessing compassion, however, is the notion that compassion is the key determining factor that places an act which remains criminal beyond the reach of the criminal courts. The clear message is that, if a person has acted only compassionately in providing assistance to a competent adult with a determined desire to commit suicide, then he or she will (almost certainly) not be prosecuted. Although it might be true that a suspect's compassionate motivation has always been pertinent to the exercise of discretion in the decision to prosecute generally, the clear

45 (1977) 66Cr App Rep 97, discussed by R Huxtable in Euthansia, Ethics and the Law: From Conflict to Compromise (Routledge Cavendish, 2007) 60. McShane was recorded telling her mother to take an overdose and also not to tell anyone of her role in assisting the suicide for fear that she might lose her inheritance. In fact, the potential victim did not want to commit suicide and no attempt was made.

46 See n 4, above, para 43(7) of the Policy: 'the suspect pressured the victim to commit suicide'.

47 Ibid, para $43(3)$.

48 Ibid, para 45(4).

49 Ibid, para 45(5). 
articulation of the crucial role of compassion provided by the Policy places compassion at the very core of not only current policy, but also identifies it as an impetus for potential legal change.

With respect to the ethical underpinnings of the Policy, it is clear that autonomy is also an essential prerequisite to a decision not to prosecute. It is my contention, however, that in drawing a line between ethically acceptable and ethically unacceptable complicity in suicide, the Policy has primarily adopted a motive-centred approach. Of course, autonomy is vital, as are the other factors but, as I will go on to discuss, the notion of compassion which the Policy seems to embrace encompasses consideration of the reasons why the victim chose death and also, arguably, the assumption that their choice was autonomous. It is difficult to conceive of a situation in which one's act of assisting in suicide could be viewed as an act of compassion in the absence of there being 'a voluntary, clear, settled, and informed decision to commit suicide'. If the victim was not completely certain that suicide presented the least worst option under the circumstances, how could it be recognised as objectively compassionate to assist or encourage such a person towards suicide? For this reason, I contend that in the majority of cases where there is no evidence to suggest obvious foul play, assessing compassion will be the most important prosecutorial task.

Such a motive-based approach is novel and perhaps surprising, because compassion has not generally been regarded as legally important within common law jurisdictions. Traditionally, English law does not recognise any motive as legally determinative, although, it would be inaccurate to describe motive as entirely irrelevant. For example, motive, or at least justification for the defendant's action, is crucial in establishing certain justificatory defences such as self-defence, and motive may also be relevant to sentencing. ${ }^{50}$ Generally, however, proof of an act (actus reus) together with the requisite mental state (mens rea) indicates liability regardless of any motive which might be regarded as changing the moral nature of the act. Within the realm of assisted dying, however, one exception to this principle applies to doctors who hasten the death of patients suffering great pain and/or

50 As Norrie remarked, 'Having insisted upon a strict legal code so as to protect the liberty of the individual, it transpires that the individual's liberty is ultimately dependant not upon the rule of law at all but on a group of men operating with a wide discretion at the sentencing stage'. See A Norrie, 'From Criminal Law to Legal Theory: The Mysterious Case of the Reasonable Glue Sniffer' (2002) 65 Modern LR 538. Norrie also argues that when it is convenient, motive may be considered relevant, for example in permitting doctors to prescribe the contraceptive pill to girls under the age of 16 (see Gillick $v$ West Norfolk AHA [1985] 3 All ER 402 (HL)). See also, A Ashworth, 'The Treatment of Good Intentions', in A Simester and A Smith, Harm and Culpability (Oxford University Press, Oxford, 1996). 
anxiety as death approaches. The doctrine of double effect distinguishes medical killing, or at least hastening death, from murder in this context, provided that the primary intention of the doctor was to relieve pain and not to kill. ${ }^{51}$ This is despite the fact that generally in English law, intention may be regarded as present when the defendant acted with the realisation that the consequence (death or very serious injury) was virtually certain to follow such act. ${ }^{52}$ The fact that the doctor might have realised only too well that death was virtually certain to follow the administration of a large dose of pain relieving and/or sedative medication does not amount to criminal intention, as it would in any other context, provided the doctor demonstrated only the desire to relieve suffering and not the desire to kill. ${ }^{53}$ Moreover, within the realm of assisted dying, the Law Commission has recommended that the issue of motive should be further considered, with the possibility of a partial defence to murder (in the context of euthanasia) on the grounds of mercy. ${ }^{54}$ Thus, the DPP's recognition of a motive (compassion) as a key determining factor is novel but not entirely without precedent within the context of assisted dying.

51 The double effect doctrine was first outlined in the case of $R v$ Adams [1957] Crim LR 365. Devlin J (as he then was) famously said that a doctor, '... is entitled to do all that is proper and necessary to relieve pain and suffering, even if the measures he takes may incidentally shorten life'. More recently however, experts in palliative care have argued that it is a fallacy to say that appropriate use of analgesia and/or sedative medication causes death. See for example, N Sykes and A Thorns, 'Sedative Use in the Last Week of Life and the Implications for End-of-life Decision Making' (2003) 163 Archives of International Medicine 341-344.

52 See $R v$ Woollin [1998] 4 All ER103. Interestingly, J Keown opined that Woollin might have a 'chilling effect on the provision of much needed palliative care and leave patients dying in pain and distress', (see Euthansia, Ethics and Public Policy: An Argument Against Legalisation (Cambridge University Press, Cambridge 2002) 28-9. However, there is no evidence to suggest that Keown's post Woollin fears have transpired. For example the double effect doctrine was successfully relied upon by Dr Howard Martin in 2005. See 'Doctor Cleared of Murder Investigated Over 12 Other Deaths', The Independent, Friday, December 16 2005. More recently, Martin has apparently confessed to hastening the deaths of a number of other patients. See 'GP 'admits hastening' terminal patient's death', June 19 2010, < http://news. bbc.co.uk/1/hi/england/wear/10356194.stm >.

53 Also, in relation to a doctor withdrawing life-sustaining treatment, motive is central to a rather curious provision of the Mental Capacity Act 2005 relating to the withdrawal of life-sustaining treatment. S 4(5) states, 'Where the determination relates to life-sustaining treatment he must not, in considering whether the treatment is in the best interests of the person concerned, be motivated by a desire to bring about his death'. See J Coggon, 'Ignoring the Moral and Intellectual Shape of the Law after Bland' (2007) 27(1) Legal Studies 110.

54 The Law Commission (2006) Murder, Manslaughter and Infanticide'. Project 6 of the Ninth Programme of Law Reform; Homicide (Law Com No 304, London). 
In some civil law jurisdictions, however, the presence of compassion has long been recognised as legally determinative. For example, in Germany, compassionate killing, even in the absence of a request from the victim, reduces what would otherwise be murder to the crime of manslaughter. ${ }^{55}$ Similarly, in Columbia, killing another in order to end intense suffering stemming from a serious or incurable illness or a serious injury is recognised as compassionate homicide rather than murder. ${ }^{56}$ As previously mentioned, Switzerland's position on the assisted suicide prohibits only selfishly motivated assistance with suicide, which will also obviously involve consideration of whether the suspect acted compassionately in the interests of the deceased.

Penney Lewis ${ }^{57}$ has considered the role of compassion as the mechanism of legal change with particular reference to a proposal put forward in France by the French National Bioethics Advisory Committee ${ }^{58}$ (CCNE). In 2000, the CCNE reversed their former opposition to any relaxation in the French prohibition against assisted dying, stating, in an opinion entitled 'End of Life, Ending Life, Euthanasia', ${ }^{59}$ that euthanasia might be permissible in exceptional circumstances. The CCNE did not advocate substantive legal change but, rather than a defence of euthanasia, might halt the judicial investigation where the defendant was shown to have acted compassionately. The proposal, which has not been adopted, suggested that an interdisciplinary commission should evaluate the motivations of the accused and provided that the suspect was evidently motivated by 'concern to end suffering, respect for a request made by a patient, compassion in the face of the inevitable', ${ }^{60}$ a judge would then drop the charges. Clearly, within this proposal, the role of the commission and the judge, in evaluating motivation in order to determine whether a prosecution should be continued, is analogous to the quasi-judicial role of UK prosecutors in assessing whether the suspect was wholly motivated by compassion prior to determining whether it is in the public interest to prosecute. As Lewis notes, Pascale Boucard has considered the CNNE's proposals, observing that 'the systematic character of the decision to discontinue prosecution

55 Arts 211-3 of the German Penal Code.

56 Art 106 of the Columbian Penal Code. For further consideration of the Columbian legal position, see Sabine Michlowski, 'Legalising Active Voluntary Euthanasia Through the Courts: Some Lessons from Columbia' (2009) 17 Med L Rev 183-218.

57 See P Lewis, Assisted Dying and Legal Change (Oxford University Press, Oxford 2007). Also P Lewis, 'The Evolution of Assisted Dying in France: A Third Way?' (2005) 13(4) Med L Rev 44.

58 Comite Consultatif National d'Ethique (CNNE), see Lewis ibid.

59 See Lewis (n 58, above) 109.

60 Ibid, 110. 
would shortly lead to the decriminalization of the act'. ${ }^{61}$ While in relation to France, this observation is purely hypothetical, we might now consider whether the systematic character of the decision not to prosecute in England and Wales, because the suspect was wholly motivated by compassion, will inevitably lead to the legalisation of compassionate assistance in suicide.

There are a number of reasons why Boucard's view is compelling. First, as assisting in suicide is increasingly perceived as not being subject to criminal prosecution, society will come to expect exactly that. As Baroness Hale in Purdy stated, '[p]eople need and are entitled to be warned in advance so that, if they are of a law-abiding persuasion, they can behave accordingly' ${ }^{62}$ Thus, the DPP has informed people precisely how to 'behave accordingly' with respect to assisting suicide whilst remaining law-abiding. It is of course true that the law has not changed, but nevertheless, as Greasley has noted, '... a previously unofficial policy of non-prosecution in these cases has been ordered to be made official'. ${ }^{63}$ Furthermore, in the event that some prosecutions do occur, sympathy for the defendant's compassionately motivated predicament may increasingly call into question the nature and purpose of such an offence. ${ }^{64}$

Consequently, with respect to any future parliamentary debates, the effective decriminalisation of certain modes of assisting suicide will inevitably affect how this issue is perceived by even those who are theoretically opposed to any relaxation of the prohibition. Although, as Lord Justice Brooke observed, 'successive governments, and Parliaments, have set their face against euthanasia', ${ }^{65}$ previous opposition to any form of assisted dying operated in a climate of considerably less overt tolerance. It may be of some significance that by 2005 evidence of some shift in Parliamentary attitude was arguably emerging, when the House of Lords Select Committee on Lord Joffe's Assisted Dying for the Terminally Ill Bill ${ }^{66}$ adopted a more neutral stance than previous

${ }^{61}$ P Boucard, 'Commentary on the Opinion of the CNNE of 27 January 2000 entitled "end of life, ending life, euthanasia", (2000) 48(6) Laennec 10 at 15. See Lewis (Ibid) 111.

62 Purdy HL (n 2, above) at para 59.

63 K Greasley, 'Case comment: R (Purdy) v DPP and the Case for Wilful Blindness' (2010) 30(2) Oxford Journal of Legal Studies 301-326, at 307.

64 See, for example, the case of Gilderdale, discussed below and at n 38. Given that, as R Huxtable has observed, any 'jury will be drawn from a population apparently in thrall to the idea of assisted suicide' (Huxtable, n 29 at 67) jury nullification is likely.

65 Re A (Conjoined Twins) [2001] Fam 147, 239, 211.

66 See the Assisted Dying for the Terminally Ill Bill - First Report, Sessions 2004-05, <www.parliament.uk>. Lord Joffe's Bill began its journey embracing voluntary euthanasia but was later considerably diluted to include only PAS. 
Committees on the issue of physician-assisted suicide (PAS) ${ }^{67}$ Furthermore, at the time the final Joffe Bill was defeated (by 148 to 100 votes), suicide tourism was an altogether novel phenomenon, with little consequent need to legislate in order to control its practice. Five years later, the need for control has become more apparent. In consideration of the fact that a continuing legal prohibition offers only the opportunity to retrospectively determine whether the assistance fell within accepted boundaries after the chance of preventing the victim's death has passed, ${ }^{68}$ pre-emptive control through legalisation may seem increasingly attractive.

Of course, sceptics might argue that the fact that the state tolerates certain criminal acts does not inevitably lead to their legalisation, ${ }^{69}$ and indeed, there might be some advantages to continuing a policy of tolerance within a regime of continued prohibition. ${ }^{70}$ Detailed consideration of these issues is beyond the scope of this paper, but in partial consideration of the first argument, there are a number of reasons why an assisted suicide may be distinguished from other tolerated (criminal) activities. First, it is a trite observation, but people are naturally concerned with how they might die, and in an increasingly aged society such concerns will inevitably preoccupy a greater proportion of the population. Evolving societal values also bring weight to bear upon this increasingly precarious area of criminal law. As Griffiths, Weyers, and Adams have observed, there may be a link between a 'post-materialistic value orientation, ${ }^{71}$ and the growing importance placed by individuals within society upon

${ }^{67}$ In 1994, a House of Lords Select Committee on Medical Ethics firmly opposed any relaxation in the law. (See 'Report of the Select Committee on Medical Ethics', HL Paper 21, London: Her Majesty's Stationary Office.) Thus, the neutral stance adopted by the Committee convened to consider the Joffe Bill demonstrates some shift in Parliamentary attitudes.

68 Or at least having ascertained, for example, that the person wanting to die is suffering unbearably from a terminal illness and that there are no other means of alleviating the suffering.

${ }^{69}$ For example, a degree of tolerance in relation to the personal use/consumption of illegal drugs has not resulted in legalisation.

${ }^{70}$ For example, Greasley ( $\mathrm{n} 64$, above) argues that in compelling the DPP to promulgate such a Policy, the House of Lords have taken a retrograde step. Greasley's contention is that the previous practice of turning a blind eye to assisted suicide, in a climate of uncertainty as to what exactly constituted prosecutorial policy, was a preferable state of affairs.

${ }^{71}$ Identified by R Inglehart, The Silent Revolution (Princetown University Press, Princetown, NJ 1977), who argued that there is a connection between prosperity and value orientation, such that people living without threat to their livelihood move beyond concerns over safety and security, focusing instead on freedom, self-expression, and quality of life. Discussed in J Griffiths, $\mathrm{H}$ Weyers and M Adams, Euthanasia and the Law in Europe (Hart Publishing, Oxford 2008) 15 . 
self-determination. ${ }^{72}$ In turn, the nature of the so-called offence renders cases highly news-worthy and so the media repeatedly pushes this issue into the public consciousness. Protagonists ${ }^{73}$ in the debate seem to enjoy public sympathy, and the issue of whether an assisted suicide should be legalised is one which appears to garner public support. ${ }^{74}$ Finally, the organisation, Dignity in Dying, may also play a significant role in potential legalisation through their campaign to reform the law. Already their support of Debbie Purdy has led to the promulgation of the Policy which has confirmed that those motivated by compassion to assist in suicide are extremely unlikely to face prosecution. Thus, the Policy colludes with other influences and circumstances to render legalisation increasingly probable.

\section{ASSESSING THE VICTIM}

In his interim guidelines, the DPP identified the fact that if the victim had a terminal illness, a severe and incurable physical illness, or a severe degenerative physical condition, it would count as one of the factors against prosecution. An overview of the cases in which a prosecution was not deemed to be in the public interest supports the idea that the physical condition of the victim has indeed been considered relevant to the question of whether or not to prosecute, and so it seemed sensible for the DPP to identify this issue as having some bearing upon the exercise of prosecutorial discretion. However, in response to representations yielded from the public consultation, ${ }^{75}$ the DPP has removed this factor,

72 See Griffiths and others, ibid, at 525. In conclusion to their discussion of which countries are most likely to legalise some form of assisted dying, and notwithstanding that 'prediction is very difficult', Griffiths and Weyers predict that England is likely to be the next country to legalise some form of assisted dying.

73 For example, Debbie Purdy and, for very different reasons, Kay Gilderdale.

74 For example, a recent BBC poll, carried out for a 'Panorama' programme on the Gilderdale case, suggests that almost three-quarters of people support the assisted suicide in cases where the person wanting to die has a terminal illness. Support falls to just below half if the illness is painful but not terminal. See Poll Support for Mercy Killings, at $<$ http://news.bbc.co.uk/1/hi/ uk/8489744.stm $>$. These results are similar to the results of other such polls. As the House of Lords Select Committee on the Assisted Dying for the Terminally Ill Bill reported, following consideration of a number of polls, 'It is evident that there is a great deal of sympathy, at least for the concept of euthanasia'. See n 67, above, at para 218.

75 More than 1500 respondents argued that it may be discriminatory to include factors relating to the health and disability status of the victim. See the 'Public Consultation Exercise on the Interim Policy, Annex B - Equality and Diversity Impact Assessment', para 25 <www.cps.gov.uk>. Perhaps also pertinent to this aspect of the final Policy is that following publication of the interim guidelines in September 2009, an Early Day Motion 302 was laid in the House of Commons calling for the policy to be withdrawn on the 
so the current position invites the presumption that the physical condition of the victim should have no bearing upon the decision to prosecute. It should perhaps be noted, however, that the DPP maintains that the factors listed are not exhaustive and so other unspecified factors may indeed be pertinent to the decision. Accordingly, it may be that the health of the victim remains relevant as one of the other possible factors despite not featuring in the Policy, and we should not forget that the DPP has stated that the risk of prosecution remains unchanged. Nonetheless, it seems reasonable to contend that removing any reference to the victim's health where previously it featured invites the presumption of a change in this aspect of the policy.

Clearly, by removing this factor, the DPP has attempted to allay the fears of those for whom the inclusion of this factor implied that the lives of people with such conditions have less value. Indeed, perhaps one of the most compelling arguments put forward against the legalisation of any form of assisted dying is that there might be a disproportionate impact on disabled or seriously ill people. The idea that individuals with a serious illness or disability would 'qualify' for an assisted death, and thereby suffer discrimination because of the perception that their life has reduced value, links into slippery slope arguments; the contention being that any legal model of assisted dying would soon render the option of an assisted death into an obligation for certain groups. ${ }^{76}$ On this issue, Greasley highlights the danger of employing objective thresholds: '. . . the law cannot impose value of life thresholds in assisted suicide without, by extension, engaging in value of life comparisons directed at not just individuals, but at whole groups of sufferers' ${ }^{77}$ Whilst it may be difficult to refute the notion that differentiating between individuals on the grounds of health might necessitate a degree of 'value of life' appraisal, evidence suggests that such an appraisal does not invariably lead to negative consequences for certain groups. In jurisdictions where physician-assisted dying (PAD) has been legalised, notably the Netherlands and Oregon, there is no evidence that legalising PAD via a system which imposes objective health-based limitations

basis that it overrides the will of Parliament by indicating to would-be offenders how to avoid prosecution, and also puts vulnerable people at grave risk.

${ }^{76}$ For example see J Keown, Euthanasia, Ethics and Public Policy: An Argument against Legalisation (Cambridge University Press, Cambridge 2002). For a response to Keown's treatise, see S Smith, 'Evidence for the Practical Slippery Slope in the Debate on Physician-assisted Suicide and Euthanasia' (2005) 13(1) Med L Rev 17-44, and 'Fallacies of the Logical Slippery Slope in the Debate on Physician-assisted Suicide and Euthanasia' (2005) 13(2) Med L Rev 224-43. See also, H Lillehammer, 'Voluntary Euthanasia and the Logical Slippery Slope Argument' (2002) 61 (3) Cambridge LJ 54550 .

77 Greasley, n 64, above, 321. 
upon access to PAD leads to negative consequences for certain groups. ${ }^{78}$ Such evidence, however, may be insufficient to ease the concerns of those who may perceive themselves to be at risk from any such policy, and we must recognise that this is a highly subjective issue. Sheila MacLean has considered this thorny issue, observing that:

People who want to facilitate autonomous choices at the end of life do not thereby disvalue disability... while impairments may be disabling as much because of society's failure to accommodate them as for any other reason, nonetheless the fact of disability may be relevant to how people see their future. For example, the suffering associated with cancer is disabling, but it is also clearly relevant to the way in which people manage their healthcare decisions and their end-of-life choices. ${ }^{79}$

Moving from consideration of the ethics of recognising certain conditions as relevant to prosecutorial Policy, to contemplation of how prosecutors will actually resolve this dilemma in practice, we might question whether it is even realistic to suppose that prosecutors will now cease to be influenced by the physical condition of the victim. Indeed, can any understanding of compassion exclude consideration of the victim's health? In the context of prosecutorial tolerance of an assisted suicide, one might ask how it could ever be viewed as 'compassionate' to assist a person in suicide unless the victim had some serious illness or condition from which death would provide a release. The very notion of compassion is, I would argue, inextricably linked to the idea that the subject of one's emotions is suffering. For example, Nussbaum $^{80}$ relates compassion to Aristotle's account of pity, which rests on the premise that there is serious suffering. ${ }^{81}$ Consequently, any objective assessment of whether a person's assistance in the suicide of another was motivated by compassion will naturally involve an assessment of whether the victim was suffering, and so the victim's reason for wanting to die and the apparent rationality of the suicide wish will be

78 See for example, JAC Rietjens and others, 'Two Decades of Research on Euthanasia from the Netherlands. What Have We Learnt and What Questions Remain?' (2009) 6 Bioethical Enquiry 271-83. See also, MP Battin and others, 'Legal Physician-assisted Dying in Oregon and the Netherlands: Evidence Concerning the Impact on Patients in "Vulnerable Groups" ' (2007) 33 JME 591-7.

79 S McLean, 'Assisted Dying: Reflections on the Need for Law Reform' (Routledge Cavendish, Oxford, New York 2007) 64.

80 See, M Nussbaum, 'Compassion: the Basic Social Emotion' (1996) 13(1) Social Philosophy and Policy 27-58.

81 Interestingly, this account of pity/compassion infers that compassion is to some degree a self-centred emotion, because it is invoked partially because of fear that the same fate could befall the person feeling compassion. 
crucial to any appraisal of the suspect's involvement. The absence of any illness, injury, or condition, which might be viewed as explaining the victim's decision to die, will invariably cast one who assists in such a suicide in an extremely unfavourable light. ${ }^{82}$ Thus, identifying the condition which gave rise to the suffering of the victim is arguably imperative to the possibility of any assistance in suicide being viewed as compassionate. For this reason, it seems inconceivable that prosecutors will now cease to take into account the health of the victim.

It is also highly probable that if one was to encourage or assist in the suicide of a person who did not have a sufficiently serious condition, from which death might (objectively) be viewed as providing an escape, there might be immediate doubts over the mental capacity of the victim. It is a disturbing fact that suicide and mental illness are often linked. Thus, it seems that the factor in favour of prosecution relating to a lack of capacity ${ }^{83}$ will also necessitate an appraisal of the victim's physical and mental health. Accordingly, it appears that although the policy no longer seems to favour those who assist in the suicide of a terminally ill or severely disabled person, in reality, the absence of such a condition will be damning evidence against one so accused.

From a comparative perspective, in every other jurisdiction (except for Switzerland ${ }^{84}$ ) where some form of assisted dying is permitted, there must be medical grounds supporting the desire to die. In the Netherlands, assisted dying on request ${ }^{85}$ is permissible only where the 'patient's suffering was unbearable, and...there was no prospect of

82 Although it may be argued that a person suffering emotionally, from grief, terrible personal problems or professional disgrace for example, might equally be seen to experience serious suffering. I concede that there may be extremely rare cases where a person assisting in the suicide of such an emotionally troubled victim might be viewed as having been wholly motivated by compassion, but the likelihood of this is extremely low.

83 Para 43(2) of the Policy refers to capacity as defined by the Mental Capacity Act 2005. S 3 provides that a person lacks capacity if he or she is unable to make decisions because of being unable to; (1)(a) understand the information relevant to the decision, (b) retain that information, (c) to use or weigh that information as part of the process of making that decision, or (d) communicate that decision.

${ }^{84}$ In Switzerland, non-selfish or altruistic assistance in suicide is not an offence irrespective of the health of the deceased, provided that the deceased had decisional capacity. Interestingly, unlike other jurisdictions in which assisted dying is permitted, Swiss law on assisted suicide (codified in 1918) was shaped upon motivations of 'honour and romance' rather than motives relating to health and suffering. See SA Hurst and A Mauron, 'Assisted Suicide and Euthanasia in Switzerland: Allowing a Role for Non-physicians' (2003) 326(1) BMJ 271-3.

${ }^{85}$ The Termination of Life on Request and Assisted Suicide (Review Procedures) Act 2002. 
improvement ${ }^{86}$ and both doctor and patient were convinced that 'there was no reasonable alternative in light of the patient's situation' ${ }^{87}$ Similarly, in Belgium, a doctor who performs euthanasia does not commit a crime if he or she ensures that 'the patient is in a medically hopeless situation of persistent and unbearable physical or mental suffering that cannot be alleviated, resulting from a serious or incurable disorder caused by illness or accident'. ${ }^{8}$ Finally, in Oregon, assisted suicide is available only to those with an imminently terminal illness, which is defined as 'an incurable and irreversible disease that has been medically confirmed and will, within reasonable medical judgement, produce death within six months' ${ }^{89}$

In comparison with the jurisdictions mentioned above, a position which appears to disregard the health of the victim and the reasons behind the suicide wish clearly ignores the context within which an assisted suicide is sought. The denial of the crucial reality behind this issue is also reflected in the Policy's disapproval of medical involvement, which I go on to consider below. Moreover, it should be noted that whereas a majority within society appear to support the assisted suicide for the terminally ill, support is far less forthcoming if the victim is not terminally ill. As noted by Baroness Hale of Richmond in Purdy:

... in attitudinal surveys the British public have consistently supported assisted dying for people with a painful or unbearable incurable disease from which they will die, if they request it, while rejecting it for people with other reasons for wanting to die. ${ }^{90}$

It seems that whether or not there is a specific reference to the condition of the victim, some form of health-focused assessment is unavoidable if compassion is the guiding principle. By adopting compassion as the central determining issue, the DPP has effectively retained the discretion to consider the physical condition of the victim, without subjecting the Policy to allegations of discrimination. Does this mean that the lives of the seriously ill or disabled are intrinsically less valuable? Or, even that certain lives might eventually be labelled as unliveable, should certain conditions 'qualify' as ones which get a green light for an assisted

${ }^{86}$ Ibid. See also J Griffiths, H Weyers and M Adams, Euthanasia and the Law in Europe (Hart Publishing, Oxford 2008) 84. The unbearable suffering must Ibid.

88 Ibid, Griffiths and others, 312.

89 The Oregon Death with Dignity Act 1994.

90 HL decision in Purdy (n 2, above), para 66, citing evidence from the National Centre for Social Research, British Societal Attitudes, The 23rd Report (London, 2007) ch 2. 
suicide? In a society capable of recognising moral boundaries, the answer to both questions is, of course, 'no'. The implications are simply that, in the event that a person with such a condition autonomously determined that life was too great a burden to bear, evidence regarding the reasons for this decision would be relevant when determining if a person assisting had acted compassionately or with bad motive.

\section{MEDICS BEWARE}

Significantly, in the final version of the Policy, the DPP added to the list of factors tending in favour of prosecution the fact that:

... the suspect was acting in his or her capacity as a medical doctor, nurse, other healthcare professional, a professional carer [whether for payment or not], or as a person in authority, such a prison officer, and the victim was in his or her care. ${ }^{91}$

In consideration of the DPP's rationale for this addition, the summary of responses and commentary in relation to new factors in favour of prosecution is interesting. ${ }^{92}$ Concerns that the interim guidelines had presented an unfair bias against carers working in a care or nursing home environment in comparison with other healthcare workers clearly contributed to the decision to widen the scope of healthcare workers regarded unfavourably by the Policy. ${ }^{93}$ Thirty-four per cent of respondents who commented in the public consultation exercise expressed the view that it is inappropriate to single out such care workers in the absence of any broader factor covering those working in a healthcare environment generally. At the same time, $83 \%$ of respondents agreed that it was desirable to regard the involvement of carers as a factor tending in favour of prosecution. Consequently, the DPP determined that it was desirable to extend this factor to include any healthcare professional or worker. In the absence of any further explanation as to why carers were initially singled out, and subsequently, why medical professionals and workers in general should now be at greater risk of prosecution, we might question the reasoning behind this factor.

91 See Policy, para 14, n 4, above.

92 See 'Public Consultation Exercise on the Interim Policy for Prosecutors in Respect of Cases of Assisted Suicide Issued by the Director of Public Prosecutions Summary of Responses', at s 3 (New Factors Identified in favour of Prosecution) (www.cps.gov.uk).

93 The interim guidelines had included as a factor in favour of prosecution; (14) The suspect was paid to care for the victim in a care/nursing home environment. 
In relation to physicians, other evidence suggests that there is greater public support for PAS than there is for family-assisted suicide (FAS). A 2001 survey reported that $84 \%$ of respondents supported the legalisation of PAS, whereas just $54 \%$ supported the legalisation of FAS. ${ }^{94}$ Whilst this survey focused on opinions regarding legalisation rather than opinions regarding prosecution policy, the ethical considerations underpinning these issues are almost identical, aside from the fact that there might be a more obvious preference for expert over amateur assistance if legalisation were to occur. Thus, the opinions gathered by the DPP in the consultation exercise appear to be at odds with public opinion on this issue generally. If compassionate, reluctant assistance in suicide is now tolerated subject to the guidelines, we should ask why such tolerance is less likely to be extended to healthcare workers and professionals? Indeed, viewed comparatively, healthcare workers are far less likely to be motivated by factors other than compassion. The potential 'gain' of a free hospital bed vacated by the deceased, for example, is a relatively insignificant benefit compared with the potential gains which a relative might reap, ranging from being freed from their role as primary carer to the financial gain enjoyed as a beneficiary to the victim's estate.

The role of certain healthcare workers also puts them at greater risk of prosecution. For example, doctors and other healthcare professionals might now have concerns over criminal liability arising from difficult end-of-life conversations and whether they might be implicated merely by answering questions or providing information. In response to such concerns the Medical Defence Union (MDU) recently stated:

[T]he MDU's advice to its members remains that doctors approached by patients for advice about suicide should not engage in discussion which assists the patient to that end. Members who are faced with requests from patients, including for example the provision of medical reports, should contact us for advice. ${ }^{95}$

In addition to the obvious role that a doctor could play in a patient's suicide, by, for example, providing pills for an overdose, specific concerns focus upon a doctor's duty towards a patient seeking an assisted suicide abroad. Dignitas, for instance, requires applicants to provide

94 C O’Neill and others, 'Attitudes to Physician and Family Assisted Suicide; Results from a Study of Public Attitudes in Britain' (2002) 28 J Med Ethics 52.

95 See C Dyer, 'Doctors Face Greater Risk of Prosecution than the Public for Assisting Suicide’ (2010) 340 BMJ 1167. 
details of their medical records prior to an assisted suicide. ${ }^{96}$ As guardians of their patients' medical records, doctors must therefore release this information in order for a patient to be considered by Dignitas. Thus, a doctor's cooperation in the knowledge of the purpose of the provision of patient records might invoke potential criminal liability. ${ }^{97}$ In less controversial circumstances, section 7 of the Data Protection Act 1998 provides a patient with a clear right of access to such information. The purpose of the request for access in this context, however, creates a dilemma for doctors. The Data Protection (Subject Access Modification)(Health) Order 2000 creates an exception to the right of access so that data which would otherwise have to be disclosed can be withheld in the event that its disclosure would be likely to cause serious harm to the physical or mental health of the data subject. Consequently, the conflicting duties of doctors faced with a request for access to medical records for the purposes of an assisted suicide may be difficult to resolve. The 'serious harm' exception to data release will be unacceptable to a patient who sees the assisted suicide to be in her best interests, as an escape from harm rather than as harm in itself. Moreover, a doctor who refuses to release data in an attempt to prevent a patient from exercising a competent and autonomous choice to travel abroad to avail themselves of a service which is legal within that jurisdiction, may be in breach of human rights legislation. ${ }^{98}$

In reality, the doctor who merely releases medical records in order for a patient to apply to an organisation such as Dignitas should not fear prosecution. Not a single doctor has been prosecuted for assisting in suicide in any capacity, ${ }^{99}$ and despite the apparently heightened risk

${ }^{96}$ For more details of the application process for Dignitas, together with discussion of suicide tourism generally see, R Huxtable, 'The Suicide Tourist Trap: Compromise Across Boundaries' (2009) 6 Bioethical Enquiry (2009) 32736.

97 Evidentially, the doctor's act in providing/releasing the information would be capable of assisting or encouraging a suicide or attempt, thereby satisfying the actus reus of the offence. Acting in the knowledge (with the foresight) that the attempt/suicide would be virtually certain to follow (see $R v$ Woollin [1998] 4 All ER103) would suffice to demonstrate that the doctor had the mens rea for the offence of assisting or encouraging suicide.

98 See A local Authority v Z (An Adult: Capacity)[2004] EWHC 2817, [2005] 1 W.L.R. 959, 3 All ER 280, in which a local authority attempted to prevent a patient from travelling abroad for an assisted suicide. For case comment, see $\mathrm{P}$ de Cruz, 'The Terminally Ill Adult Seeking Assisted Suicide Abroad: The Extent of the Duty Owed by a Local Authority' (2005) 13(2) Med L Rev 257-67.

99 For example, Dr Michael Irwin escaped prosecution following his attempt to assist a friend, although the GMC struck him off. See 'Euthanasia Doctor is Struck Off', BBC News, September 27 2005, <www.news.bbc.co.uk/1/hi/ health/4286470.stm $>$. In fact, Irwin's friend, who was suffering from cancer, died without taking the pills. Dr Irwin was also questioned by 
now elucidated by the Policy, it seems that a policy which tolerates a relative pushing a wheel-chair bound victim onto the flight to Zurich and then on to the Dignitas premises could hardly sanction the prosecution of a GP who merely provided the victim's medical notes. ${ }^{100}$

While evidence suggests that healthcare professionals are less likely to be prosecuted than the Policy might lead us to believe, it is illustrative of a clear prosecutorial desire to deter healthcare workers from becoming embroiled in assisting in patient suicides. With little evidence of meaningful discourse on the subject, the Policy indicates that there are good reasons for regarding healthcare workers with greater suspicion than relatives who assist, for example. The inclusion of this factor accords with the overall message of the Policy by seeking to ensure that it remains extremely difficult to obtain meaningful or practical assistance in suicide within the jurisdiction. This might be justifiable if the Policy succeeded in reducing the number of suicides or even controlling who was able to access such assistance, but, as previously mentioned, given the availability of assisted suicide in Switzerland this seems unlikely. Moreover, in an increasingly aged society where ever larger numbers are surviving to endure the difficulties that great age can bring, the nonavailability of expert information and advice about how to commit suicide, ${ }^{101}$ may lead to an increase in botched suicide attempts. As Seale states, ' $\ldots$ it takes expertise to achieve a humane assisted death. By ruling out medical involvement, the DPP's policy ensures that no such expertise will accumulate'. ${ }^{102}$

Suzanne Ost ${ }^{103}$ has considered the relative merits of medicalised and de-medicalised assisted dying and although there are clearly many benefits to a less medicalised approach in comparison with a completely medicalised system, such as the Dutch model, a completely amateur

police in 2006 for assisting May Murphy to travel to Switzerland for an assisted suicide. He had previously admitted advising five other Britons who were considering travelling to Dignitas. (See R Huxtable, n 29, above.) It should be noted, however, that as a prominent right-to-die campaigner, Irwin's (former) occupation as a physician was perhaps only incidental to his involvement in allegedly assisting in suicide.

100 Such an act being only of minor assistance (see para 45(3) of the Policy).

101 With only illicit advice being available, for example, an Australian doctor, Nitschke, has organised suicide workshops for the over 50s in English seaside retirement havens, as well as publishing advice on the internet and even offering for sale suicide drug testing kits. See "Dr Death' Philip Nitschke reveals secrets of a peaceful exit', The Times, May 6 2009. Also, despite the inclusion of a factor (para 43(11)) designed to discourage people from using the internet as a means of obtaining information/advice about suicide, it remains very difficult to prevent such information from being made available.

102 See n 64, above.

103 S Ost, 'The De-medicalisation of Assisted Dying: Is a Less Medicalised Model the Way Forward?' (2010) 18(4) Med L Rev ?? 
approach is extremely problematic. Moreover, the Policy is refusing to acknowledge that the vast majority of people seeking assisted suicide are doing so because the medical means of maintaining good health are proving inadequate, hence the issue is inherently medical. Even if there is compelling evidence that doctors are opposed to PAS, ${ }^{104}$ there should at least be some medical engagement with patients seeking an assisted suicide, if only in order to explore the reasons why a person wants to die and whether there are any alternatives. Furthermore, if one accepts that the tolerance of compassion assisted suicide will inevitably lead to the eventual legalisation of some form of assisted dying, it is inconceivable that any legalisation would permit only amateur assistance in suicide. By seeking to prevent any tentative medical involvement, might it be that the Policy is preventing society from gathering experience and wisdom upon which an ethically acceptable path might be navigated?

\section{CONCLUSION}

In their legislative capacity, the House of Lords rejected Lord Falconer's attempted amendment to the Coroners and Justice Bill, which would have legalised assisting someone to travel abroad for an assisted suicide subject to safeguards. ${ }^{105}$ It is, therefore, perhaps ironic that the indirect effect of the House of Lords decision in Purdy is the confirmation that certain modes of compassionately assisting in suicide are effectively decriminalised without any safeguards relating to the victim, other than age and mental capacity, and these are purely retrospective. In a democratic society, it should not fall to the DPP to resolve controversial moral dilemmas, but, in the absence of Parliamentary intervention, he has been forced to do just that. Charged with an unenviable task, the DPP sought to both rationalise and clarify the way in which prosecutorial discretion is exercised over complicity in suicide.

104 For example see C Seale, 'Legalisation of Euthanasia or Physician-assisted Suicide; Survey of Doctor's Attitudes' (2009) 23 Palliat Med 205, 209. The survey revealed that the majority of doctors were opposed to any legalisation of PAS or voluntary euthanasia. Interestingly, in 2009, the Royal College of Nursing dropped its opposition to assisted dying in favour of neutrality on the issue. See 'RCN neutral on assisted suicide', BBC news, July 25 $2009<$ www.news.bbc.co.uk/1/hi/health/8167455.stm>.

105 The amendment to the Bill, which was defeated in 2009, required that two medical practitioners would assess that the person seeking suicide was both terminally ill and mentally competent. Additionally, the person would have to make a declaration of their intention to die in writing witnessed by an independent person. 
By adopting a motive-centred approach, in which compassion is identified as the key determining factor, thereby confirming that it is not appropriate to seek to punish the majority of those who assist in suicide in this context, the Policy treads a sensitive path. The clear recognition of compassion as being crucial to ethically acceptable complicity in suicide is an important development. Some elements of the Policy, however, demonstrate the difficulty in outlining a morally coherent approach in the face of a law which presents an evidently unsustainable prohibition, particularly with respect to some of the tension between assisted suicide at home and abroad. Born from the public consultation exercise, some of the factors also have a knee-jerk quality to them. The removal of the factor relating to the health of the victim, for example, seeks to address concerns over discrimination at the expense of plausibility and coherence. The reality of the context within which people seek to control the end of their life is similarly rejected by the inclusion of the factor relating to the involvement of healthcare professionals. Whilst the DPP had a duty to determine the final policy based on the public consultation findings, some of the consequences are disappointing.

Although Cartwright has observed that 'regrettably it will take a legislature with considerably more courage than ours has demonstrated to broach this difficult area', ${ }^{106}$ in the face of mounting pressure, in addition to the other factors which I have identified as exerting an influence over this issue, it may soon become impossible for the current legal fudge to endure. Ultimately, if a practice judged by many to be undesirable is, in any case, occurring, even those opposed to it may recognise that rather than merely having the opportunity for retrospective appraisal and possible punishment, control through legalisation is a more satisfactory approach.

106 Nick Cartwright, '48 Years On; Is the Suicide Act Fit for Purpose?’ (2009) 17(3) Med L Rev 467. 